\title{
The Alarming Community Concern on Household Insecticide Exposure and Usage
}

Abdul Alif $A H^{a}$, Muhammad Lokman $M^{b}$, Afzan $M Y^{b}$, Siew $P L^{c}$, Nik Fakhuruddin $N H^{d}$, Hussin $M^{e}$

${ }^{a}$ Department of Critical Care Nursing, Kulliyyah of Nursing, International Islamic University of Malaysia, Jalan Hospital Campus, 25200 Kuantan, Pahang, Malaysia

${ }^{b}$ Department of Basic Medical Sciences, Kulliyyah of Nursing, International Islamic University of Malaysia, Jalan Sultan Ahmad Shah, Bandar Indera Mahkota, 25200 Kuantan, Pahang, Malaysia

'Department of Professional Nursing Studies, Kulliyyah of Nursing, International Islamic University of Malaysia, Jalan Hospital Campus, 25200 Kuantan, Pahang, Malaysia

${ }^{d}$ School of Health Sciences, Health Campus, University Sains Malaysia, 16150 Kubang Kerian, Kelantan, Malaysia

${ }^{e}$ Herbal Medicine Research Centre, Institute for Medical Research, Jalan Pahang, 50588 Kuala Lumpur, Malaysia

\section{ABSTRACT}

The utilization of insecticide in a household environment is a necessity especially for those living in the tropical country such as Malaysia. Tropical climate with high humidity and urbanization lead to pests breeding problem hence contributing to the spread of vector diseases such as dengue. Household insecticide such as aerosol sprays, coils and mats are made from a combination of chemicals from type 1 pyrethroid group which are recognized as safe and have minimal toxic effects on human. However, there have been cases of accidental and intentional insecticide poisoning which demonstrates the lack of studies on factors of knowledge, attitude and practice of insecticide usage, the exposure as well as clinical presentation since the symptoms are similar to other compounds which may lead to misdiagnosis. These insecticide chemicals do not only exert toxic effects to pest but to human too due to its highly toxic characteristic which causes diseases such as asthma, cancer, and other diseases following short or long-term exposure to the chemicals. As a result, there is a growing community health concern regarding the uncertainty and risk of insecticide exposure to human. Thus, the risk assessment of community's knowledge, attitude and practice regarding the insecticide are essential in aiding towards the development of improving insecticide profile, safer insecticide handling and exploration of insecticide alternative. This will result in better insecticide awareness, as well as minimize the insecticide risk exposure and its adverse health effects to the community.

KEYWORDS: Community health, insecticide awareness, insecticide exposure, insecticide practice, insecticide toxicity

\section{INTRODUCTION}

Malaysia is a tropical country which is suitable for the infestations of insect pests in urban household

\section{Corresponding Author}

Asst. Prof. Dr. Muhammad Lokman Md Isa

Department of Basic Medical Sciences,

Faculty of Nursing,

International Islamic University of Malaysia,

Jalan Sultan Ahmad Shah,

Bandar Indera Mahkota,

25200 Kuantan, Pahang, Malaysia.

Tel No: +609-5704000

E-mail: lokman@iium.edu.my such as ants, cockroaches, mosquitoes and many more which are responsible for spreading communicable diseases by serving as biological and mechanical vectors for vector borne disease. ${ }^{10,27}$ According to a report, the highest vector borne disease is dengue which is a mosquito-borne disease with the incidence rate of 328.8 cases per 100000 population reported for the year 2017 in Malaysia. ${ }^{4}$ The occurrence of cases in the country is influenced by high humidity and urbanization which enhance the breeding of the mosquito especially in urban residential areas. ${ }^{18}$ The Ministry of Health, Malaysia acknowledged that dengue as a major community 
health concern and has taken necessary steps by employing vector control program as the gold standard to prevent the disease outbreak. ${ }^{3}$ The program encourages the community to engage in vector control practice at home such as the usage of household insecticide as a method of disease prevention. ${ }^{32}$ Hence, vector control method in a form of insecticide aerosol sprays is a necessity for households in Malaysia. ${ }^{16}$

Most of the commercial household insecticide aerosol sprays are made from a combination of chemicals of type 1 pyrethroids group. ${ }^{7}$ These insecticide chemicals are recognized by WHO to be safe and have minimal toxic effects to human. ${ }^{42}$ However, there have been reported cases of accidental and intentional insecticide poisoning which demonstrates the lack of studies on factors of knowledge, attitude and practice of insecticide usage, the exposure as well as clinical presentation since the symptoms are similar to other compounds which may lead to misdiagnosis. ${ }^{8,9}$

These insecticide chemicals do not only exert toxic effects to pest but to human too, due to its highly toxic characteristic. ${ }^{43}$ Pyrethroids insecticide also poses health hazard threat following short and long term exposure which can cause diseases such as asthma, cancer, diabetes and other diseases. ${ }^{24,26}$ It exhibits the toxic effects through generating multiple nerve action potential as well as interacting with enzyme and receptor which leads to tremors, hyperexcitability and cellular damage. ${ }^{17}$

According to case study by Cha and $\mathrm{Kim}^{8}{ }^{8} 39.9 \%$ of the patients admitted due to acute exposure of pyrethroid presented with respiratory problems; while Bradley and Cage $^{5}$ indicated abdominal symptoms, vomiting and seizure due to the exposure. Other studies suggested that long term exposure of pyrethroid and pyrethrin are associated with cancer, developmental, endocrine, neuronal and reproductive diseases. ${ }^{13,22,23}$

These insecticide chemicals can be exposed to human through inhalation, ingestion and dermal contact as a result of insecticide household application. ${ }^{28}$ The use of carpets and home furniture may accumulate the deposited insecticide chemicals which could enhance the exposure risk through inhalation and accidental indigestion of insecticide aerosol. ${ }^{31}$ According to studies, the use of insecticide in the house environment may permit insecticide chemicals to be released in an aerosol form and deposited as dust which can be exposed directly and indirectly to human especially child due to hand-tomouth behaviour. ${ }^{21,35}$ Therefore, it is important to highlight the current knowledge, attitude and practice on household insecticide usage to increase awareness on the exposure and the proper handling practice in ensuring a safer home environment among the community.

\section{Knowledge on insecticide}

In Malaysia, the insecticide in aerosol spray form is commonly used in the household as disease prevention method. ${ }^{40}$ According to a study involving the community in Seremban district, a state in Malaysia, it is reported that about $54.16 \%$ of respondents used insecticide aerosol spray at home due to its effectiveness in killing mosquito. ${ }^{29}$

However, recent studies suggested extensive usage in the household environment may have negative health effects due to the lack of knowledge regarding the toxic effects of the insecticide spray. ${ }^{28,38}$ The poor knowledge on areas of insecticide application and storage at home, can contribute to human exposure through ingestion of contaminated food. ${ }^{30}$ Hence, knowledge on a household insecticide, its usage and side-effects are important to determine the community exposure risk and assess the exposure of insecticide in a household environment.

\section{Level of knowledge on household insecticide}

Household environment is known as a common indoor environment where most insecticide sprays are used. The usage of insecticide contributes to indoor contamination and exposure treat to human. ${ }^{30}$ The insecticide exposure is a community health concern and it is attributed to the lack of knowledge regarding the household insecticide product. $^{28}$

A study, showed that there is an inadequate knowledge regarding insecticide spray consumer product with $53 \%$ and $48 \%$ of respondents depended on information from neighbours and salesmen respectively on choice of insecticide spray rather than the health inspector, in which the information reliability may vary according to personnel 
knowledge and education level. ${ }^{30}$ The study also suggested limited knowledge in a community led to improper insecticide application in the home environment, which contributed to insecticide exposure.

\section{Knowledge on the use of insecticide}

The application of insecticide in aerosol spray form is a targeted application. However, there is a tendency of over spraying due to the high pressure of the aerosol causing the insecticide to spread to non-targeted areas which increases the risk of potential exposure. ${ }^{24}$

The frequency and time of insecticide application also contribute to excessive usage of insecticide. A study suggested that $40 \%$ of respondents applied insecticide daily, $14 \%$ used the insecticide when the infestation and breeding season appeared, and 53\% preferred to use it at night. ${ }^{30}$ Hence, daily usage of insecticide can be excessive according to homeowner's preference. The extensive daily usage of insecticide is an exposure concern since exposure takes place during preparation, application and completion. ${ }^{11}$

\section{Knowledge on the side-effects of insecticide exposure}

Insecticide is considered to be a hazardous chemical which is widely used in the home environment. ${ }^{39}$ Home usage of insecticide may introduce the chemicals within to the indoor environment. This raises exposure concern as common chemicals in the insecticide such as pyrethroid is not easily broken down and can stay in the environment for a long period. ${ }^{11,24}$

These insecticide chemicals have common side effects on eyes, skin and respiratory system. ${ }^{11,30}$ Some insecticide users are aware of the common acute side effects from their experience in handling the insecticide. According to a study, respondents were aware of the side effects of insecticides usage with $70 \%$ aware about skin irritation, $22.9 \%$ about skin burns effects, and $12.9 \%$ about respiratory illness. ${ }^{20}$ Based on previous studies, there are many other side-effects of insecticide exposure which have been reported but remain undefined to community knowledge due to lack of study. ${ }^{5,8}$

\section{Attitude towards insecticide}

Although most homeowners prefer to use insecticides in their homes, there is some notion regarding the danger on toxic effects of insecticide based on the users' experiences. ${ }^{15,25}$ This notion is determined by the user's attitude such as negligence on the safe practice of insecticide usage which contributed to the improper usage of insecticide. ${ }^{16}$

The notion is also influenced by the type of insecticide preference which varies from province to province as well as awareness regarding the insecticide. ${ }^{20}$ Therefore, most homeowners are insensitive to the dangers of insecticide due to personal perception, socio-demographic and prevalence of cases, which can be a concern for the safety of insecticide usage.

\section{Perception towards insecticide}

Accidental poisoning in the home environment is possibly due to personal risk. One of the most significant personal risk is personal perception towards the insecticide. ${ }^{12}$ The perception of the user is the key to encourage a person to engage in insecticide safe practice behaviour. Insecticide users' perception is usually influenced by their own experience.

According to a study, $87.1 \%$ of insecticide users are aware regarding the harmful effects of insecticide based on their observation on side effects such as skin irritation upon contact. ${ }^{20}$ Another study also noted that association between respondents' experience and safe insecticide practice is significant. ${ }^{25}$

From a previous study, experiences can create awareness on insecticide toxicity. However, a study showed respondents reluctance to engage in safe insecticide handling practice due to negligence despite having awareness. ${ }^{25}$ Hence, a person's perception can determine the outcome of safety behaviour to prevent the exposure.

\section{Social demographic influence}

There are many epidemiological studies which examined the relationship of exposure to insecticide and related diseases since there is community health 
interest on human factors such as individual perception information which varies according to gender and demographic factor. ${ }^{37}$

According to a study by Cabrera and Leckie, ${ }^{6}$ female insecticide users were found to perceive higher health risk association than the male users, hence tend to engage in safe practice behaviour. The finding is also similar to another study which showed that female pose higher concerns regarding insecticide use than male. ${ }^{2}$ It is known that female would likely perceive higher self-health conscious as they tend to take an active role in managing their health. ${ }^{40}$

The perception of insecticide health risk also may vary from place to place such as from urban areas to agricultural areas due to the extensive usage of the product and the community common practices. ${ }^{20} \mathrm{~A}$ study in Sweden suggested that community living near agricultural areas are aware of insecticide health risk and conveyed negative perception towards the insecticide usage. ${ }^{2}$ Other study involving people in high streets from European countries also indicated that there was awareness regarding potential health effects with insecticide usage but refused to adopt safe practice due to their believes that damage has already occurred. ${ }^{36}$ Therefore, the perception and believe of potential risk of insecticide exposure depends on individual's judgments on the severity of health consequences. ${ }^{19}$

\section{Prevalence of exposure cases}

Exposure of insecticide has become a significant community health concern all over the world particularly in developing countries. Exposure can be acute or chronic, however most of the common emergency cases which required urgent medical attention were acute exposure. ${ }^{33}$ Acute exposure can be accidental or intentional through inhalation, ingestion, injection and dermal contact. ${ }^{1}$

According to $\mathrm{WHO}^{41}$ it is estimated that more than 250000 deaths had arisen from 3 million cases of acute insecticide exposure. In Malaysia (1999-2001), exposure to insecticide made up $16.4 \%$ out of total 10 220 and $44.3 \%$ out of 4485 of accidental and intentional acute exposure emergency cases respectively. ${ }^{34}$ The horrifying pattern of incidence rate may reflect the extent of insecticide accessibility to the community in their homes, workplace and industry as well as the community's low perceived health risk and awareness on insecticide usage. ${ }^{14}$

\section{Insecticide practice}

Accidental exposure of insecticide in general population is a result of insecticide used in home environment due to the introduction of the chemicals to the environment. ${ }^{43}$ However, the exposure also may be enhanced by human factor ie poor practice of insecticide application at home.

A study by Nalwanga and Ssempebwa, ${ }^{30}$ indicated the poor practice of insecticide spraying where $50 \%$ of the respondents sprayed the insecticide directly to the pest whilst flying. This causes the insecticide to spread and end up on the floor as home dust. The study also suggested that the practice may encourage excessive spraying of insecticide aerosol, as much of the chemicals go to non-target areas.

Another study indicated poor practice on insecticide application as the insecticide can be found in home dust collected in kitchen areas. ${ }^{24}$ It is known that insecticide application may cause insecticide to be deposited on food and drink. ${ }^{39}$

Other practices such as poor storage, hygiene and miss handling were also found to be associated with exposure. Practices such as transferring product to a home container without labelling, the use of faulty insecticide device and poor hand hygiene were found to be the sources of exposure. ${ }^{11}$

\section{CONCLUSION}

The utilization of insecticide in a household environment is a necessity among some community especially those living in tropical countries with pests breeding problem due to the high humidity and urbanization. However, there is a growing community health concern regarding the uncertainty and risk of insecticide exposure to human due to its negative health effects.

Therefore, the risk assessment of community's knowledge, attitude and practice regarding the insecticide are essential towards the development of improved insecticide profile, safer insecticide handling practices and exploration of insecticide alternative. This will result in better insecticide 
awareness, and minimize insecticide risk exposure and its adverse health effects to the community.

\section{DECLARATION OF INTEREST}

The authors declare no conflict of interest.

\section{ACKNOWLEDGEMENTS}

The author would like to thank the Department of Basic Medical Sciences, Kulliyyah of Nursing International Islamic University Malaysia.

\section{REFERENCES}

1. Adnan L, Kamaldin J, Mohamad N, et al. The risk of accidental chemical poisoning cases among children ( $\leq 12$ Years Old) admitted to Hospital University Sains Malaysia: 5 Years Review. J Clinic Toxicol. 2013;3(5):177.

2. Ahmed N, Englund J-E, Ahman I, et al. Perception of pesticide use by farmers and neighbors in two periurban areas. Science of the Total Environment. 2011;412:77-86.

3. Al-Dubai SAR, Ganasegeran K, Alwan MR, et al. Factors affecting dengue fever knowledge, attitudes and practices among selected urban, semi-urban and rural communities in Malaysia. Southeast Asian Journal of Tropical Medicine and Public Health. 2013;44(1):37.

4. Bernama. Dengue Fever Most Prevalent Infectious Disease in Malaysia. Sun Media Corporation Sdn Bhd 2017.

5. Bradberry SM, Cage SA, Proudfoot AT, et al. Poisoning due to pyrethroids. Toxicological reviews. 2005;24(2):93-106.

6. Cabrera NL, Leckie JO. Pesticide risk communication, risk perception, and selfprotective behaviors among farmworkers in California's Salinas Valley. Hispanic Journal of Behavioral Sciences. 2009;31(2):258-72.

7. California MotMVCAo, (MVCAC) CR. Ecological \& Human Health Assessment Report Integrated Mosquito and Vector Management Program $\square$. 2013.

8. Cha YS, Kim H, Cho NH, et al. Pyrethroid poisoning: features and predictors of atypical presentations. Emerg Med J. 2013:emermed2013-202908.

9. Chandra A, Dixit MB, Banavaliker JN. Prallethrin poisoning: A diagnostic dilemma. Journal of anaesthesiology, clinical pharmacology. 2013;29(1):121.
10. Control mCGoV. A research agenda for malaria eradication: vector control. PLoS medicine. 2011;8(1):e1000401.

11. Damalas CA, Eleftherohorinos IG. Pesticide exposure, safety issues, and risk assessment indicators. International journal of environmental research and public health. 2011;8(5):1402-19.

12. El-Zaemey S, Heyworth J, Glass DC, et al. Household and occupational exposure to pesticides and risk of breast cancer. International journal of environmental health research. 2014;24(2):91-102.

13. Emara AM, Draz El. Immunotoxicological study of one of the most common over-the-counter pyrethroid insecticide products in Egypt. Inhalation toxicology. 2007;19(12):997-1009.

14. Fathelrahman Al, Ab Rahman AF, Mohd Zain Z. MS 04-044: demographic features of drug and chemical poisoning in northern Malaysia. Clinical Toxicology. 2005;43(2):89-94.

15. Gul S, Ibrahim S, Wasif N, et al. Mosquito repellents: killing mosquitoes or yourselves. J Sci Innovative Res. 2013;2(6):1052-7.

16. Gupta A. Pesticide use in South and South-East Asia: environmental public health and legal concerns. American Journal of Environmental Sciences. 2012;8(2):152.

17. Gupta RC, Milatovic D. Insecticides. Biomarkers in toxicology: Elsevier; 2014. p. 389-407.

18. Hanim A, Razman M, Jamalludin A, et al. Knowledge, attitude and practice on dengue among adult population in Felda Sungai Pancing Timur, Kuantan, Pahang. International Medical Journal Malaysia. 2017;16(2).

19. Hansen J, Holm L, Frewer L, et al. Beyond the knowledge deficit: recent research into lay and expert attitudes to food risks. Appetite. 2003;41 (2):111-21.

20. Hlongwana KW, Mavundza EJ, Mohapi EP, et al. Vector-control personnel's knowledge, perceptions and practices towards insecticides used for indoor residual spraying in Limpopo Province, South Africa. Parasites \& vectors. 2013;6(1):118.

21. Hoffman K, Webster TF, Sjödin A, et al. Toddler's behavior and its impacts on exposure to polybrominated diphenyl ethers. Journal of Exposure Science and Environmental Epidemiology. 2017;27(2):193.

22. Jaacks LM, Staimez LR. Association of persistent organic pollutants and non-persistent pesticides with diabetes and diabetes-related health 
outcomes in Asia: A systematic review. Environment international. 2015;76:57-70.

23. Ji G, Xia Y, Gu A, et al. Effects of nonoccupational environmental exposure to pyrethroids on semen quality and sperm DNA integrity in Chinese men. Reproductive Toxicology. 2011;31(2):171-6.

24. Julien R, Adamkiewicz G, Levy JI, et al. Pesticide loadings of select organophosphate and pyrethroid pesticides in urban public housing. Journal of Exposure Science and Environmental Epidemiology. 2008;18(2):167.

25. Karunamoorthi K, Yirgalem A. Insecticide risk indicators and occupational insecticidal poisoning in indoor residual spraying. Health Scope. 2013;1(4):165-72.

26. Koureas $M$, Tsakalof A, Tsatsakis A, et al. Systematic review of biomonitoring studies to determine the association between exposure to organophosphorus and pyrethroid insecticides and human health outcomes. Toxicology letters. 2012;210(2):155-68.

27. Lee C-Y, editor Tropical household ants: pest status, species diversity, foraging behavior and baiting studies. Proceedings of the 4th International Conference On Urban Pests Pocahontas Press, Blacksburg, Virginia; 2002.

28. Loroño-Pino MA, Chan-Dzul YN, Zapata-Gil R, et al. Household use of insecticide consumer products in a dengue-endemic area in México. Tropical Medicine \& International Health. 2014;19(10):1267-75.

29. Mia MS, Er A, Pereira JJ. Identifying the sources of dengue infection and prevention practices at household level in Seremban District, Malaysia. Journal of Environmental Science and Technology. 2017;10(5):238-44.

30. Nalwanga E, Ssempebwa JC. Knowledge and practices of in-home pesticide use: a community survey in Uganda. Journal of environmental and public health. 2011;2011.

31. Nielsen SS, McKean-Cowdin R, Farin FM, et al. Childhood brain tumors, residential insecticide exposure, and pesticide metabolism genes. Environmental health perspectives. 2010;118 (1):144.

32. Ong S-Q. Dengue vector control in Malaysia: A review for current and alternative strategies. Sains Malaysiana. 2016;45(5):777-85.

33. Paudyal BP. Poisoning: pattern and profile of admitted cases in a hospital in central Nepal. JNMA J Nepal Med Assoc. 2005;44(159):92-6.
34. Rajasuriar R, Awang R, Hashim S, et al. Profile of poisoning admissions in Malaysia. Human $\&$ experimental toxicology. 2007;26(2):73-81.

35. Refaie AAE-R, Ramadan A, Mossa A-TH. Oxidative damage and nephrotoxicity induced by prallethrin in rat and the protective effect of Origanum majorana essential oil. Asian Pacific journal of tropical medicine. 2014;7:S506-S13.

36. Remoundou K, Brennan M, Sacchettini G, et al. Perceptions of pesticides exposure risks by operators, workers, residents and bystanders in Greece, Italy and the UK. Science of the Total Environment. 2015;505:1082-92.

37. Rudel RA, Attfield KR, Schifano JN, et al. Chemicals causing mammary gland tumors in animals signal new directions for epidemiology, chemicals testing, and risk assessment for breast cancer prevention. Cancer. 2007;109 (S12):2635-66.

38. Trunnelle KJ, Bennett DH, Tulve NS, et al. Urinary pyrethroid and chlorpyrifos metabolite concentrations in Northern California families and their relationship to indoor residential insecticide levels, part of the Study of Use of Products and Exposure Related Behavior (SUPERB). Environmental science \& technology. 2014;48(3):1931-9.

39. U.S. Department of Housing and Urban Development (HUD). Healthy Homes Issues: Pesticides -- Use, Hazards, and Integrated Pest Management. Washington DC 20410: Office of Healthy Homes and Lead Hazard Control; 2006.

40. Wong LP, Shakir SMM, Atefi N, et al. Factors affecting dengue prevention practices: nationwide survey of the Malaysian public. PloS one. 2015;10(4):e0122890.

41. World Health Organization (WHO). The impact of pesticides on health: Preventing intentional and unintentional deaths from pesticide poisoning. Geneva: WHO. 2006.

42. World Health Organization (WHO). The WHO recommended classification of pesticides by hazard and guidelines to classification 2009. 2010.

43. Zoubiri S. Chemical characteristics of aerosol insecticide deposition in indoor surfaces. Arabian Journal of Chemistry. 2011;4(2):153-8. 